\title{
Flexibility Capital and Flexibility Justice in Smart Energy Systems
}

Gareth Powells ${ }^{1}$ and Michael J. Fell

\section{Abstract}

Flexibility has increasing value across sectors of the economy, including energy. The ability to be flexible is affected by a wide variety of sociotechnical factors and determines what we term 'flexibility capital'. Levels of flexibility capital vary in populations, both absolutely and in the extent to which they are primarily derived from technological or social means, which has implications for the (dis)comfort and (in)convenience involved in economising flexibility capital. Furthermore, we argue that freedom of choice over whether and how to economise flexibility capital can be limited by factors such as financial resources, among others. In constrained systems (such as energy networks), the level of service enjoyed by the more affluent may not simply be higher than those who are less affluent, but may be directly enabled by reductions in the latter's comfort and/or convenience which may not feel fully voluntary. There is a real risk that such injustices could be locked into energy infrastructure and market design and governance for the long term as has already happened in labour markets. We introduce the concept of 'flexibility justice' as a frame for these issues of fairness. While the concepts we offer in the paper emerge from longstanding engagements with energy research contexts and they relate directly to the issues currently being debated in the energy research and policy communities, we contend that they can be related to a much broader range of issues in 21 st century economies.

Keyword: energy; flexibility; capital; justice

\section{Introducing Flexibility}

Pliancy, readiness to yield, capacity for ready adaptation to various purposes or conditions: these are the terms used by the Oxford English Dictionary when defining flexibility (Oxford English Dictionary, n.d.). Such qualities have increasingly been valued across sectors of the economy in the late 20th and early 21 st century. In the energy sector, the combination of challenges such as the need to integrate variable renewables (while maintaining security of supply at an affordable price) and the emergence of digital innovation has intensified interest in demand flexibility, which is expected to continue and deepen in the coming years.

The need to influence demand to follow supply - rather than the other way around which has been more conventional - is nothing new, with load control programmes and variable pricing structures for electricity dating back well over a century (Kidd, 1975). But the emergence of digital information and communications technology (ICT) in the management of energy systems enables this kind of production-consumption matching to be achieved in new ways, and marks a step change in the way flexibility is produced and valued.

\footnotetext{
${ }^{1}$ Newcastle University, gareth.powells@newcastle.ac.uk, UK.

2 UCL Energy Institute, michael.fell@ucl.ac.uk, UK (corresponding author).
} 
Considerable empirical and conceptual scholarship on the increasingly technological and measurement oriented nature of economies has achieved a great deal in elucidating the way new regimes of measurement and valuation come into being and have political implications that matter for those being measured (Barry and Slater, 2002; Slater and Barry, 2005). Smart metering, for example, enables energy customers, service providers and intermediaries to see patterns of energy use in much higher resolution and much closer to real time than was previously the case (McHenry, 2013). Digital platforms (such as Piclo Flex $^{3}$ ) are enabling new communications connections to be made between actors who require or can offer flexibility. Internet of Things innovation is increasingly allowing individual devices to be coordinated, controlled and monitored (Gubbi et al., 2013). Distributed ledger technology (such as blockchain) is enabling flexibility to be evidenced and authenticated, and permitting changes in supply or demand of electricity to be recognized and valued (Pop et al., 2018).

Forms of measurement and monitoring are increasingly being deployed across the power system and are part of the uncertain emergence of new, more active and multi-scalar practices of network/system operation. In this paper, however, we focus on their emergence at the intersection of the energy system and the user, focusing on how infrastructures of measurement, communication and exchange enable and in some situations induce energy users to alter their patterns of consumption in response to all kinds of signals from actors in the grid and have those changes recorded and validated.

\section{Flexibility capital}

Being flexible in terms of energy use means having the ability to shift energy use in time and space, or through changes in intensity or vector, such as switching from gas to electricity, for example. This ability is determined by, and embedded in, the combination of a wide variety of factors including working patterns, elements of social practices (such as their material/technological dependencies, meanings and required competencies), and - in the context of domestic energy use - household composition, size of electrical loads, presence of absence or energy storage, culture and religion, life stage, wealth, and so on ${ }^{4}$.

We believe that it is useful to think about the ability to be flexible as a form of capital, as originally proposed by Powells and Bulkeley (Powells and Bulkeley, 2013). As early as 1986, Bourdieu had argued for a broader understanding of capital, one which (in his case) includes social and cultural forms of value which are linked to tangible benefits or advantages:

"It is in fact impossible to account for the structure and functioning of the social world unless one reintroduces capital in all its forms and not solely in the one form recognized by economic theory. ... Capital can present itself in three fundamental guises: as economic capital, which is immediately and directly convertible into money ...; as cultural capital ... ; and as social capital, made up of social obligations ('connections'), which is convertible, in certain conditions, into economic capital..." (Bourdieu, 1986, p. 46)

\footnotetext{
${ }^{3}$ Piclo Flex is described as an "independent marketplace for buying and selling smart grid flexibility services", https://piclo.energy/flex (accessed 4 January 2019).

${ }^{4}$ Indeed, the determinants of flexibility capital are manifold, and further research is needed to better understand which are most powerful although this is beyond the scope of this perspective piece.
} 
This suggests that some entities which may not seem explicitly monetary are of value to those that possess them and can, under certain circumstances, be 'economised' such that they become capable of being circulated within markets where 'certain conditions' are present. For example, a person who can live safely in their family home for free can use this social capital to undertake unpaid internships. In our view, smart energy systems create the conditions for flexibility to be valued and, as a result, the flexibility of energy users is effectively 'capitalised'. We define flexibility capital as the capacity to responsively change patterns of interaction with a system to support the operation of that system.

Across (and within) societies there is substantial social and spatial diversity in the many factors we identify above as determinants of flexibility capital. Whether we are considering individuals, families, households, businesses, communities or other units of analysis, it follows that flexibility capital is unevenly distributed, as we unpack below.

\section{The uneven distribution of flexibility capital}

The unevenness with which flexibility capital is held is an inevitable consequence of it being embedded in heterogeneous socio-technical and socio-spatial contexts. We suggest that flexibility capital interacts with other major dimensions of difference (such as gender, age, and levels of digital inclusion) with various implications. In this paper we focus on what we consider to be the clearest of these interactions - that between flexibility capital and affluence - to show how lived experiences of smart energy are differentially affected by this intersection. Figure 1 summarizes the characteristics and consequences of these interactions.

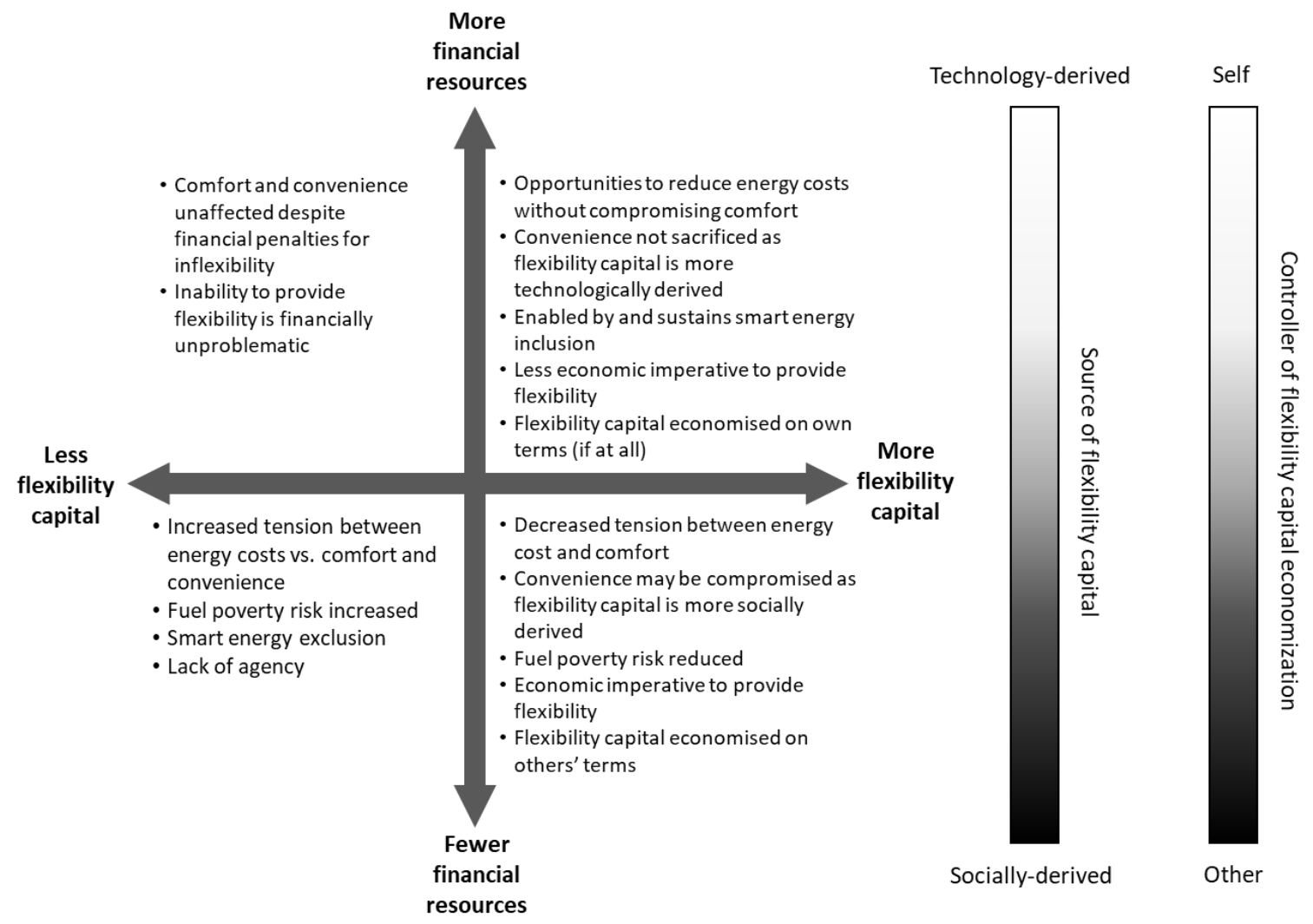

Figure 1: Generalized representation of the interaction between flexibility capital and financial resources (affluence). 
Both the top and bottom left-hand quadrants represent circumstances in which people are unable to be flexible and are therefore exposed to the (unavoidable) additional costs associated with this, or denied access to the benefits. These quadrants differ principally from each other in the degree of burden inflexibility imposes, with those who are less affluent experiencing the negative impacts more seriously. For these in the lower left-hand quadrant, their inflexibility increases the risk and severity of fuel poverty, and aggravates the tensions between fuel and other essential costs (particularly cooking costs if peak electricity costs fall at the same time as evening meals, as is likely to be the case).

The right-hand quadrants represent circumstances where people have flexibility capital, are able to economise it, and benefit from doing so. Those in the lower right-hand quadrant are therefore able to alleviate the risk and extremity of fuel poverty, while those in the upper right-hand quadrant can leverage their flexibility capital in order to realise a range of benefits. However beneath these superficial categorisations lie other important differences.

Figure 1 includes two 'gradient bars'. The first of these is intended to indicate that while flexibility capital is socio-technically derived, the relative contribution to individual 'holdings' of flexibility capital made by social and technical determinants varies. More specifically, we suggest that flexibility capital held by more affluent energy users is more likely to be derived from their ownership of energy technologies which directly afford flexibility (such as batteries and smart appliances) and their increased likelihood of having significant loads to manage. The less affluent are less likely to have access to such technologies to act as buffers between their daily practices and the flexibility valued by the grid, and as a result their flexibility capital stems more from changes to daily activities and routines.

This has practical implications for the lived experiences of smart energy services, including potential loss of comfort and inconveniences that arise when less affluent energy users trade these for reduced energy costs. In such cases, flexibility capital comes from being willing and able to alter aspects of daily life in exchange for economic rewards. Where flexibility capital is technologically derived, however, disruption to comfort and convenience can be minimised.

A second claim that pertains to this relationship (visualised in the second gradient bar in Figure 1) is that more affluent energy users have more choice over how, when and on whose terms they economise their flexibility capital, if at all. This is a consequence of the smaller part that energy costs play in their daily lives than in those of less affluent users. This difference matters because it reduces the freedom of choice experienced by less affluent energy users around economization of their flexibility capital. In essence, the lens of flexibility capital reveals that the more affluent are able to offer flexibility on their own terms, while the less affluent are subject to a greater financial pressure as to when and how to economise their flexibility. This results in a fundamental difference between the two quadrants in the balance of power between actors providing flexibility and those requesting it.

This presents, of course, a highly generalised view of the economization of flexibility capital, and many alternative scenarios may emerge. For example, those in rented housing may have access to high levels of technically-derived flexibility capital (as a result of landlord interventions, such as the installation of electric heat pumps). Nevertheless, these are still more likely to be shaped to some extent by deals struck by (and possible under direct control 
of) landlords and other actors seeking to help unlock their tenants' flexibility (e.g. Sweetnam et al., 2018).

In this section we have set out a number of ways in which flexibility capital may interact with affluence and potentially reinforce existing advantages and harms. We wish to go further than this, however, and argue that it is not simply the case that the more affluent benefit while others do not, or that all benefit to some degree. Rather, in the context of the fixed capacity of energy systems, flexibility provided by some (through the acceptance of different and, most likely, more constrained energy services) directly 'makes way' for others to enjoy an uncompromised level of service. This amounts to a zero-sum game - capped by the system capacity - in which the ability of some to enjoy the benefits of energy services may come directly at service quality cost for others. The effect of this can be compounded if the flexibility capital held by those making way is, as we suggest is more likely, socially derived. We believe this can be usefully framed as a justice issue.

\section{Flexibility justice}

In recent years energy researchers have begun to develop a body of theory and scholarship that employs notions of justice and injustice to critically analyse energy service provision experienced in a vast array of contexts around the world. This research has crystallised around the concept of energy justice, with recent themed journal issues (e.g. Jenkins et al., 2017) and books (e.g. Bickerstaff et al., 2013; Sovacool and Dworkin, 2014) consolidating these ideas and evidence of their traction in policy arenas beginning to emerge (e.g. Ofgem [2018] and through energy poverty networks such as ENGAGER ${ }^{5}$ ). The growing body of scholarship in this area takes in a broad range of issues, from subjects like access to modern energy services (Nerini et al., 2018) and impacts of solid fuel cook stoves (Haigler, 2011) which are more relevant in Global South contexts, to issues of transition (such as from coal to natural gas [Finley-Brook et al., 2018]) in existing mature energy networks.

While there has been a significant amount of research attention on energy justice considerations related to low-carbon transitions (McCauley et al., 2019), work explicitly considering the justice implications of flexibility specifically has still been somewhat limited given the scale of expectations in this area. Exceptions include work by Milchram et al. (2018) on smart grids, which along with issues around transparency, privacy, security and control, also highlights the potential for distributive justice concerns resulting from the inability of consumers to shift demand to equal extents. Such subjects are also explored (although without an explicit justice frame) in work around distributional impacts of flexibilityrelated product offerings such as time of use tariffs (Cambridge Economic Policy Associates Ltd, 2017; Hledik et al., 2017; Nicholls and Strengers, 2015; Yunusov et al., 2018). Further scholarship has considered broader social impacts of smart home technology which, while not necessarily its primary function, can enable flexible energy use (Tirado Herrero et al., 2018; Wilson et al., 2017).

We see clear intersections between the issues we raise in this perspective piece and this important work on (and related to) energy justice. We seek to contribute to these debates by to drawing attention to those aspects of energy justice which are explicitly related to

\footnotetext{
${ }^{5}$ www.engager-network.net
} 
flexibility, both to allow more precise identification of these issues and to foreground them as a specific area of concern. This is of particular importance in the context of the widespread assumption that demand flexibility will be centrally important to the decarbonisation of mature energy systems in the Global North (e.g. Commonwealth of Australia, 2017; HM Government, 2017). In other contexts energy transitions are multiple and diverse (Bridge et al., 2013) and may involve very different flexibilities as systems are extended, micro-grids emerge, sometimes informally, and demand takes on new forms.

However, we believe that the increasing prominence of flexibility as a feature of the wider economy calls for a fully developed understanding of its justice implications well beyond the energy sector alone. Examples of inequalities arising from the uneven and contextually contingent nature of flexibility capital can be found in many other sectors of the economy.

Critical research in economic geography has, for example, excavated the problematic aspects of gig-economy labour, and the lived experiences of work-life trade-offs made by workers. In many ways, flexible working arrangements, when they are part of long term employment, are found to be of advantage to both employees and employers and offer winwin instances of mutually complementary flexibility (James, 2017). However, when work flexibility comes instead of, rather than as part of, good quality employment, things can become far more problematic. The gig economy and platform labour markets that have emerged in recent years have been found to be plagued by highly gendered and racialised inequalities (van Doorn, 2017), and to pose risks to long term employment standards (Graham et al., 2017). In sum, we can learn from the labour sector that flexibility is neither inherently emancipatory nor pernicious but also that the culture and ethics of its realisation matter in terms of how it is experienced by different people in different contexts.

In a second example, connecting with emerging scholarship on the energy dimensions of transport and mobility justice, we suggest that transport inequalities and their injustices observed in recent research (Berry et al., 2016; Simcock and Mullen, 2016) could also be helpfully understood through the lenses of flexibility capital and justice. Doing so would bring into focus the flexibility-related lived experiences, (in)conveniences and subtle changes to quality and control over one's life that often go under the radar of much research. This would also do the political work of reifying that which is not often measured and therefore not often considered in policy making processes. In such an example, those who have to commute at peak times as a result of an inflexibility such as their work schedule are penalised by either paying more for train fares, or spending hours sat in traffic, or being exposed to surge pricing for taxis. In contrast, those with flexibility can avoid these burdens. Indeed, multiple flexibilities are sought and offered throughout the economy, and throughout our daily lives. Sometimes these are beneficially aligned - such as when shift work enables workers to access low cost energy - and at others these are in conflict. Some factors, such as having caring responsibilities or chronic health conditions, might limit flexibility across domains and make affected individuals more exposed to injustices.

The fact that flexibility is sought and offered in other domains of the economy which connect and interfere with people's interactions with energy systems also means that it may be possible to address the idea of flexibility capital, the insights into its diversity, and the resulting justice questions to a much broader range of issues than those within the scope of the energy justice research. We therefore suggest developing an additional concept of 'flexibility justice' which enables researchers and other stakeholders to consider in an 
integrated way the justice implications of flexibility capital across sectors. This suggestion runs with the grain of other proposals to take a more integrated view of energy, such as an agenda for work on the energy impacts of non-energy policies by (Royston et al., 2018) and the recent interest in co-benefits of energy interventions which see energy as always embedded in the wider economy (Figus et al., 2018).

Some might question the gravity of these issues; a few pennies here and there on an energy bill, or minor inconveniences suffered. If these are the costs of the flexibility needed to support a long term transition to low-carbon energy system, the harms experienced by those financially obliged to economise their capital must, we accept, be weighed against the harm expected as a result of climate change and air pollution if effective interventions are not found. We would question, however, the extent to which the risks of injustice associated with the turn to flexibility - in energy and the wider economy - have been fully thought through.

If the system becomes reliant upon and is designed around the assumption that certain groups of customers will have to be compliant and offer flexibility, this compliance becomes self-perpetuating and is likely to become normalised and effectively locked in. As consensus solidifies around flexibility and demand (rather than supply) responsiveness, there may be ever-more intense calls for it as network assets continue to be sweated. As this continues, the value of flexible demand is likely to rise, with a ratchet effect meaning that what are minor inconveniences to daily life now may establish systems of enrolment, consent, and measurement, as well as a more general normalisation of flexibility economisation which could set a path for more substantial disruptions in future. This process has unfolded already in the labour domain as has been widely researched (see Berg, 2016; Graham et al., 2017) but not clarified through the lenses of flexibility capital or flexibility justice. We see in the energy system this process unfolding around us, and unlike in the labour domain, its extent and ultimate outcomes remain undetermined.

Perhaps more fundamentally, we also think it is important to question whether it is right to treat people and the practices they perform as merely instrumental to support efficient operation of systems, particularly in the context of private ownership of many infrastructures of service provision (including energy).

\section{Conclusions and research agenda}

In this article we have introduced two new concepts, flexibility capital and flexibility justice, which we suggest can be used to reveal and frame problems that are inherent in managing constrained systems by cultivating new forms of flexibility. While a great deal of excellent research effort has already been focused on these topics, these concepts offer a useful, intuitive and accessible new vocabulary. We find that these concepts enable new collaborative research conversations while also opening up new avenues of enquiry. They are useful both analytically and politically by providing the basis for a socio-technical framework for energy research and policy-making communities to scrutinise opportunities and risks associated with demand flexibility.

We find that these concepts provide us with a useful heuristic to think clearly and to better understand in more integrated ways the real and potential impacts of flexibility in and on 
society. We see great value in applying and more fully developing these concepts through research which addresses:

1. The nature, extent and distribution of flexibility capital and (in)justices.

2. How best to recognise and include those most at risk of disadvantage in designing progressive energy service provision.

3. The relationships between the flexibilities sought and offered in different domains of the economy and aspects daily life - such as labour, energy, transport, communications and family.

4. The intersections between flexibility capital and other forms of capital - such as social and cultural capital - as well as those between flexibility justice and other justice domains - such as climate, energy and mobility justice.

5. The ways in which different units of analysis which can understood through these lenses - such as individuals, households, practices, businesses, communities.

We also see great potential in using these concepts in the development of interventions that respond to the very real possibility of injustices associated with flexibility. At least two kinds of intervention could be possible: those which seek to mitigate harms inherent when flexibility is prioritised in system governance, and those which offer alternative priorities.

We hope this perspective will stimulate debate and conversation, and that the concepts can be used, developed, or challenged by colleagues in the energy sector (where these issues are extremely pressing) and beyond.

\section{Acknowledgments}

[Blinded for peer review]

\section{References}

Barry, A., Slater, D., 2002. Technology, politics and the market: an interview with Michel Callon. Econ. Soc. 31, 285-306. https://doi.org/10.1080/03085140220123171

Berg, J., 2016. Income Security in the On-Demand Economy: Findings and Policy Lessons from a Survey of Crowdworkers. Comp. Labor Law Policy J. 47, 543-576.

Berry, A., Jouffe, Y., Coulombel, N., Guivarch, C., 2016. Investigating fuel poverty in the transport sector: Toward a composite indicator of vulnerability. Energy Res. Soc. Sci., Energy demand for mobility and domestic life: new insights from energy justice 18, 7-20. https://doi.org/10.1016/j.erss.2016.02.001

Bickerstaff, K., Walker, G., Bulkeley, H., 2013. Energy Justice in a Changing Climate: Social Equity and Low-Carbon Energy. Zed Books Ltd.

Bourdieu, P., 1986. The forms of capital, in: Richardson, J (Ed.), Handbook of Theory and Research for the Sociology of Education. Greenwood Publishing Group, Incorporated, New York, NY, USA, pp. 46-61.

Cambridge Economic Policy Associates Ltd, 2017. Distributional Impact of Time of Use Tariffs. Report to Ofgem, Cambridge, UK.

Commonwealth of Australia, 2017. Independent Review into the Future Security of the National Electricity Market: Blueprint for the Future. Department of the Environment and Energy, Australia. 
Figus, G., Turner, K., Katris, A., 2018. Energy-saving innovations and economy-wide rebound effects, in: Transitions in Energy Efficiency and Demand. Routledge, London, p. 156.

Finley-Brook, M., Williams, T.L., Caron-Sheppard, J.A., Jaromin, M.K., 2018. Critical energy justice in US natural gas infrastructuring. Energy Res. Soc. Sci., Energy Infrastructure and the Fate of the Nation 41, 176-190.

https://doi.org/10.1016/j.erss.2018.04.019

Graham, M., Hjorth, I., Lehdonvirta, V., 2017. Digital labour and development: impacts of global digital labour platforms and the gig economy on worker livelihoods. Transf. Eur. Rev. Labour Res. 23, 135-162. https://doi.org/10.1177/1024258916687250

Gubbi, J., Buyya, R., Marusic, S., Palaniswami, M., 2013. Internet of Things (loT): A vision, architectural elements, and future directions. Future Gener. Comput. Syst., Including Special sections: Cyber-enabled Distributed Computing for Ubiquitous Cloud and Network Services \& Cloud Computing and Scientific Applications - Big Data, Scalable Analytics, and Beyond 29, 1645-1660. https://doi.org/10.1016/j.future.2013.01.010

Haigler, E., 2011. Carbon Finance for Development: An Efficient Cookstove Case Study. Colo. J. Int. Environ. Law Policy 22, 283-292.

Hledik, R., Gorman, W., Irwin, N., Fell, M., Nicholson, M., Huebner, G., 2017. The Value of TOU Tariffs in Great Britain: Insights for Decision-makers (Report to Citizens Advice by The Brattle Group and University College London). London, UK.

HM Government, 2017. Upgrading Our Eergy System: Smart systems and flexibility plan. London, UK.

James, A., 2017. Work-life Advantage: Sustaining Regional Learning and Innovation. John Wiley \& Sons.

Jenkins, K., McCauley, D., Forman, A., 2017. Energy justice: A policy approach. Energy Policy 105, 631-634. https://doi.org/10.1016/j.enpol.2017.01.052

Kidd, W.L., 1975. Development, design and use of ripple control. Proc. Inst. Electr. Eng. 122, 993-. https://doi.org/10.1049/piee.1975.0260

McCauley, D., Ramasar, V., Heffron, R.J., Sovacool, B.K., Mebratu, D., Mundaca, L., 2019. Energy justice in the transition to low carbon energy systems: Exploring key themes in interdisciplinary research. Appl. Energy 233-234, 916-921. https://doi.org/10.1016/j.apenergy.2018.10.005

McHenry, M.P., 2013. Technical and governance considerations for advanced metering infrastructure/smart meters: Technology, security, uncertainty, costs, benefits, and risks. Energy Policy 59, 834-842. https://doi.org/10.1016/j.enpol.2013.04.048

Milchram, C., Hillerbrand, R., van de Kaa, G., Doorn, N., Künneke, R., 2018. Energy Justice and Smart Grid Systems: Evidence from the Netherlands and the United Kingdom. Appl. Energy 229, 1244-1259. https://doi.org/10.1016/j.apenergy.2018.08.053

Nerini, F.F., Tomei, J., To, L.S., Bisaga, I., Parikh, P., Black, M., Borrion, A., Spataru, C., Broto, V.C., Anandarajah, G., Milligan, B., Mulugetta, Y., 2018. Mapping synergies and trade-offs between energy and the Sustainable Development Goals. Nat. Energy 3, 10. https://doi.org/10.1038/s41560-017-0036-5

Nicholls, L., Strengers, Y., 2015. Peak demand and the 'family peak' period in Australia: Understanding practice (in)flexibility in households with children. Energy Res. Soc. Sci., Special Issue on Smart Grids and the Social Sciences 9, 116-124. https://doi.org/10.1016/j.erss.2015.08.018

Ofgem, 2018. Targeted charging review: minded to decision and draft impact assessment. Ofgem, London, UK.

Oxford English Dictionary, n.d. "flexibility, n.". [WWW Document]. URL http://www.oed.com/view/Entry/71523?redirectedFrom=flexibility

Pop, C., Cioara, T., Antal, M., Anghel, I., Salomie, I., Bertoncini, M., 2018. Blockchain Based Decentralized Management of Demand Response Programs in Smart Energy Grids. Sensors 18, 162. https://doi.org/10.3390/s18010162

Powells, G., Bulkeley, H., 2013. Flexibility as Socio-Technical Capital (Briefing Note No. 10), DEI Briefing Note Series. Durham University Energy Institute, Durham. 
Royston, S., Selby, J., Shove, E., 2018. Invisible energy policies: A new agenda for energy demand reduction. Energy Policy 123, 127-135. https://doi.org/10.1016/j.enpol.2018.08.052

Simcock, N., Mullen, C., 2016. Energy demand for everyday mobility and domestic life: Exploring the justice implications. Energy Res. Soc. Sci., Energy demand for mobility and domestic life: new insights from energy justice 18, 1-6. https://doi.org/10.1016/j.erss.2016.05.019

Slater, D., Barry, A., 2005. Technological Economy. Taylor \& Francis.

Sovacool, B.K., Dworkin, M.H., 2014. Global Energy Justice. Cambridge University Press.

Sweetnam, T., Fell, M., Oikonomou, E., Oreszczyn, T., 2018. Domestic demand-side response with heat pumps: controls and tariffs. Build. Res. Inf. 0, 1-18. https://doi.org/10.1080/09613218.2018.1442775

Tirado Herrero, S., Nicholls, L., Strengers, Y., 2018. Smart home technologies in everyday life: do they address key energy challenges in households? Curr. Opin. Environ. Sustain., Sustainability governance and transformation 2018 31, 65-70. https://doi.org/10.1016/j.cosust.2017.12.001

van Doorn, N., 2017. Platform labor: on the gendered and racialized exploitation of lowincome service work in the 'on-demand' economy. Inf. Commun. Soc. 20, 898-914. https://doi.org/10.1080/1369118X.2017.1294194

Wilson, C., Hargreaves, T., Hauxwell-Baldwin, R., 2017. Benefits and risks of smart home technologies. Energy Policy 103, 72-83. https://doi.org/10.1016/j.enpol.2016.12.047

Yunusov, T., Lorincz, M., Torriti, J., 2018. Role of household activities in peak electricity demand and distributional effects of Time-of-Use tariffs. Presented at the British Institute of Energy Economics 2018, Oxford, UK, p. 24. 